\title{
PREEXISTING MATERNAL DISORDERS - RISK FACTORS FOR NEWBORN CONGENITAL ANOMALIES
}

\author{
Elena Braha ${ }^{1}$, Alina Costina Luca ${ }^{2}$ \\ ${ }^{\prime}$ Medical Genetics Department, "Sf. Maria” Emergency Hospital for Children, Iasi \\ ${ }^{2}$ Pediatric Cardiology Clinic, "Sf. Maria” Emergency Hospital for Children, Iasi
}

\begin{abstract}
Congenital anomalies may be determined by genetic or environmental factors or a combination of the two factors. Maternal disease can affect fetal development through specific effects of metabolic products or maternal antibody transfer. Identifying mothers and pregnancies at risk as well as providing a teratogenic risk discussion and appropriate documentation is aimed at reducing potential teratogenic effects of maternal diseases.
\end{abstract}

Keywords: maternal diseases, teratogen, congenital anomalies

Congenital anomalies may be determined by genetic or environmental factors or a combination of the two occurring during prenatal development stages. It is estimated that about $10-15 \%$ of congenital anomalies are the result of the action of environmental (internal or external) factors on fetal development (1). It means that approximately $1 / 250$ newborn have congenital anomalies caused by an environmental factors. Teratogens are any agents (medications, drugs, chemicals, physical, environmental agent, infections, maternal diseases) that cause a permanent abnormality in structure or function, restriction of growth, or death of the embryo or fetus. (2) The effects of a teratogen on the embryo or fetus depend on the nature of the agent and some other factors (dose, route, length of exposure, the embryonic developmental stage at the time of exposure, the genetic susceptibility of the mother and embryo/fetus). During the first two weeks of gestation, teratogens commonly kill the embryo and lead to miscarriage. (3) Some women have health problems before they become pregnant that could lead to pregnancy complications. Maternal disease can affect fetal development through several mechanisms: specific effects of metabolic products (toxic metabolic end product, maternal underproduction of an essential metabolic product) or maternal antibody transfer.

\section{OBESITY}

Maternal obesity during pregnancy is associated with adverse outcomes that include macrosomia, hypertension, pre-eclampsia, gestational diabetes mellitus and fetal death. (4-6) Some studies indicates that maternal obesity could lead to perturbation of the normal development and maturation of the immune system of the fetus in utero. (7) Other studies have noted that children of obese mothers had a temporary accelerated development of cognition and language, followed by a rapid decline until 18 months of age, especially regarding language. (8)

\section{DIABETES MELLITUS}

Birth defects in diabetic pregnancy is $10 \%$, higher than the general population (3\%). Hyperglycemia leads to myoinositol uptake inhibition that is essential for embryonic mitosis and development of neural tube. $(9,10)$ Maternal pregnancy-associated plasma protein-A seems to be a biomarker for maternal diabetes and large-for-gestational-age newborn. (11)

Some studies notice a correlation between elevated hemoglobin A1c (HbA1c) levels and the incidence of major congenital anomalies in infants of diabetic mothers. $(12,13)$ HbA1c which exceed $11.5 \%$ are associated with congenital abnormalities

Corresponding author:

Alina Costina Luca, "Sf. Maria” Emergency Hospital for Children, 62 Vasile Lupu Street, Iasi

E-mail: acluca@yahoo.com 
in $66 \%$ of the offspring: transposition of the great vessels, ventricular septal defect (VSD), and dextrocardia are the most common heart anomalies, anencephaly, spina bifida, and hydrocephaly are the major nervous system malformations. (14) It seems that maternal diabetes affects the temporal expression pattern of gene encoding molecules involved in heart development. (15)

Rare malformations include situs inversus and caudal dysplasia, vertebral and renal anomalies, imperforate anus, radius aplasia, renal agenesis and dysplasia, and other defects. Caudal dysplasia syndrome, with varying degrees of sacral agenesis, is occasionally associated with defects of the palate and branchial arches and occurs in 1\% of diabetic offspring. $(16,17)$ In 2015, Xiang AH et al suggest a correlation between maternal diabetes and autism spectrum disorders. (18)

\section{THYROID DISORDERS}

Thyroid disorders are common in general population, much more common in the female it is to be expected that they will appear during pregnancy. Maternal hypothyroidism is mainly due to autoimmune thyroid disease. Some results showed significant differences in IQ of children of mothers who had unrecognized subclinical hypothyroidism during pregnancy, the fetus depending entirely on maternal thyroid hormones for the first 12 weeks of pregnancy when the fetal thyroid appear. (19)

Untreated hypothyroidism is associated with low birth weight and increased risk of spontaneous miscarriage and perinatal mortality. (20) Combined maternal and fetal hypothyroidism occurs mostly in regions with dietary iodine deficiency.

Hyperthyroidism during pregnancy is usually due to Basedow Graves disease. Neonatal thyrotoxicosis is transitory, lasting several months but affected children could have goiter, exophthalmos, agitation, tachycardia, periorbital edema, high appetite, hyperthermia, cardiomegaly, cardiac failure, and hepatosplenomegaly. (21)

\section{HYPOPARATHYROIDISM}

Chronic hypocalcemia is less common than hypercalcemia. The causes include chronic renal failure, congenital and acquired hypoparathyroidism, vitamin D deficiency, pseudo-hypoparathyroidism and hypomagnesemia. There is no established treatment plan for hypoparathyroidism during pregnancy because some animal studies have suggested the potential for dose-dependent fetal toxicities (for example, growth impairment, skeletal malformations and cardiovascular anomalies). (22) Infants of mothers with untreated hypoparathyroidism and low maternal calcium may have parathyroid hyperplasia and transient hyperparathyroidism during the fetal and neonatal periods. Congenital hyperparathyroidism should be considered in neonates presenting with respiratory distress, chest deformity, bone demineralization and subperiosteal reabsorption occurs in the long bones, pulmonary artery stenosis, ventricular septal defect (VSD) and muscle hypotonia. $(23,24)$

\section{NUTRITIONAL DEFICIT}

Folate deficiency may lead to congenital anomalies (neural tube defects, orofacial clefts, cardiac anomalies), anemia and spontaneous abortions, pre-eclampsia and intra-uterin growth retardation. Pregestational supplementation of folic acid (400 $\mu \mathrm{g} /$ day) prevents neural tube defects. (25) The high doses of folic acid in early pregnancy reduced, also, the risk of VSD. (26) However, some experimental studies support the idea that folic acid taken during the first few weeks of pregnancy is linked to epigenetic changes in fetal DNA, leading to an increased risk of childhood asthma and allergies. (27) Other studies conducted to date suggest that maternal folate exposure is not associated with children allergies. (28) Maternal iron deficiency has a direct influence on neonatal iron stores and birth weight. This deficit can lead to cognitive and behavioural problems in childhood. Calcium deficiency is associated with pre-eclampsia and intra-uterine growth restriction. (25)

DNA polymorphism-cofactor diet hypothesis development (DDCD - dietary cofactor DNA polymorphism - D) support that schizophrenia is due to fetal brain abnormalities caused by the interaction between genetic mutations and maternal nutritional co-factors (eg folate, cobalamin or pyridoxine) which are insufficient in maternal diet. (29) Retinoic acid, the active metabolite of vitamin A, plays significant signaling roles in embryogenesis. It is well known that either an excess or a deficiency of vitamin A results in congenital malformations, including eye malformations, such as rudimentary eyelids, microphthalmia, exophthalmia, external ear malformations (microtia, anotia), cardiovascular anomalies (small heart, persistent truncus arteriosus, transposition of great vessels), diaphragmatic hernia or undescended testis. (30) Poor maternal nutritional status, for example chronically undernourished Indian women with little or no in- 
take of animal protein in first trimester of pregnancy had infants with significantly higher birth weights. (31)

\section{AUTOIMMUNE DISORDERS. SYSTEMIC LUPUS ERYTHEMATOSUS}

Systemic lupus erythematosus (SLE) is a systemic inflammatory autoimmune disease which can affect the mother tegumentary and musculoskeletal systems as well as the fetus. SLE is characterized by immune hyperreactivity with pathogenic autoantibody formation. For exemple, first-trimester early abortion associated with maternal antiphospholipid antibodies which include lupus anticoagulant and anticardiolipin antibodies. SLE is also associated with increased frequency of preeclampsia, prematurity, growth retardation with newborns small for gestational age. Neonatal lupus syndromes (newborn with dermatologic, cardiac and hepatic abnormalities) is due to passive transfer of anti-Ro/SSA and/or anti-La/SSB antibodies (anti-nuclear autoantibodies) in some babies of mothers with autoimmune disease. The cardiac manifestations include conduction abnormalities (first-, second-, and third-degree atrio-ventricular block), endocardial fibroelastosis and cardiomyopathy. $(32,33)$

\section{MYASTHENIA GRAVIS}

Myasthenia gravis is an immune-mediated disorders caused by serum antibodies binding to the nicotinic acetylcholine receptor (anti-AchR antibodies), essential for neuromuscular transmission, resulting in progressive weakness and fatigue of voluntary muscles. Some studies showed that placental transfer of maternal anti-AChR antibodies to the fetus can cause increased risk of spontaneous abortions or premature births or, in about $10 \%$ of newborns, a transient neonatal myasthenia gravis with hypotonia, respiratory distress and feeding difficulties which commonly resolve in 4-6 weeks. In some cases was reported congenital multiple

\section{REFERENCES}

1. Brent R.L. The cause and prevention of human birth defects: what have we learned in the past 50 years? Congenit Anom (Kyoto) 2001; 41:3-21.

2. Enid Gilbert-Barness. Teratogenic Causes of Malformations, Ann Clin Lab Sci Spring 2010 vol. 40 no. 2, 99-114

3. Wilson J.G. Current status of teratology. General principles and mechanisms derived from animal studies. In: Handbook of Teratology (Wilson JG, Fraser FC, Eds), Plenum Press, New York, 1977; vol 1, pp 147-174. contractures in newborns, craniofacial dysmorphisms, cutaneous edema, kyphosis/scoliosis, multiple pterygia and low-set ears. $(34,35)$

\section{PHENYLKETONURIA}

Phenylketonuria is a rare disorder affecting phenylalanine metabolism, transmitted in an autosomal recessive manner, associated with plasma phenilalanine concentrations greater than $1,000 \mu \mathrm{mol} / \mathrm{L}$. Phenylalanine has a teratogenic effect during pregnancy causing intrauterine and postnatal growth retardation, microcephaly, intellectual disability, cardiovascular defects (double-chambered right ventricle, tetralogy of Fallot, and ventricular septal defects). (36,37) Optimal phenylalanine maternal concentrations should be strictly maintained throughout pregnancy to reduce the risk of congenital abnormalities. (38)

\section{MATERNAL FIRST TRIMESTER FEVER}

Neural tube defects (anencephaly, spina bifida, encephalocele) have a complex etiology, involving both genetic and environmental factors. $(39,40)$ Some studies have indicated that the reduced folate carrier gene (SLC19A1) is associated with an increased risk of neural tube defects (NTDs). The risk for NTDs was influenced by the interactions between the $S L C 19 A 1$ (rs1051266 GG/GA) variant and maternal first trimester fever. (41)

\section{CONCLUSION}

In conclusion, recognition of human teratogens offers the opportunity to prevent certain types of congenital malformations. This literature study demonstrates the continued need to evaluate the maternal health status when we are dealing with a children with congenital anomalies. Identifying mothers and pregnancies at risk as well as providing a teratogenic risk discussion and appropriate documentation is aimed at reducing potential teratogenic effects of maternal diseases.

4. Naeye R.L. Maternal body weight and pregnancy outcome. Am J Clin Nutr 1990; 52:273-279

5. Andreasen K.R., Andersen M.L., Schantz A.L. Obesity and pregnancy. Acta Obstet Gynecol Scand 2004; 83:1022-1029.

6. Cedergren M.I., Selbing A.J., Kallen B.A. Risk factors for cardiovascular malformation: a study based on prospectively collected data. Scand Work Environ Health 2002; 28:12-17.

7. Wilson R.M., Messaoudi I. The impact of maternal obesity during pregnancy on offspring immunity. Mol Cell Endocrinol. $2015 \mathrm{Jul} 30$. pii: S0303-7207(15)30035-6. 
8. Torres-Espinola F.J., Berglund S.K., García-Valdés L.M., Segura M.T., Jerez A., Campos D., Moreno-Torres R., Rueda R., Catena A., Pérez-García M., Campoy C. PREOBE team. Maternal Obesity, Overweight and Gestational Diabetes Affect the Offspring Neurodevelopment at 6 and 18 Months of Age - A Follow Up from the PREOBE Cohort. PLoS One. 2015 Jul 24; 10(7):e0133010. doi: 10.1371/journal.pone.0133010.eCollection 2015.

9. Sadler T.W. Embryology of neural tube development. American journal of medical genetics. 2005; 135C: $2-8$

10. Baker L., Piddington R. Diabetic embryopathy: a selective review of recent trends. Diabetes Complicat 1993; 7:204-212.

11. Wells G., Bleicher K., Han X., McShane M., Chan Y.F., Bartlett A., White C., Lau S.M. Maternal Diabetes, Large-for-Gestational-Age Births, and First Trimester Pregnancy-Associated Plasma Protein-A. J Clin Endocrinol Metab. 2015 Jun; 100(6):2372-9.

12. Loeken M.R. Advances in understanding the molecular causes of diabetes induced birth defects. J Soc Gynecol Invest 2006; 13:2-10.

13. de Vigan, Verite V., Vodovar V. Diabetes and congenital anomalies data from Paris registry of congenital anomalies. 1985-1987. Reprod Toxicol 2000; 14:76.

14. Nielsen G.L., Sorensen H.T., Nielsen P.H., Sabroe S. Glycosylated hemoglobin as predictor of adverse fetal outcome in type I diabetic pregnancies. Acta Diabetol 1997; 34:217-222.

15. Bohuslavova R., Skvorova L., Cerychova R., Pavlinkova G. Gene expression profiling of changes induced by maternal diabetes in the embryonic heart. Reprod Toxicol. 2015 Jun 11. pii: S0890-6238(15)00154-9.

16. Kucera J. Rate and type of congenital anomalies among offspring of diabetic women. J Reprod Med 1971; 7:73-82.

17. Passarge E. Congenital malformation and maternal diabetes. Lancet 1965; 1:324-325.

18. Xiang A.H., Wang X., Martinez M.P., Walthall J.C., Curry E.S., Page K., Buchanan T.A., Coleman K.J., Getahun D. Association of maternal diabetes with autism in offspring. JAMA. 2015 Apr 14; 313(14):1425-34.

19. Murphy N.C., Diviney M.M., Donnelly J.C., Cooley S.M., Kirkham C.H., Foran A.M., Breathnach F.M., Malone F.D., Geary M.P. The effect of maternal subclinical hypothyroidism on IQ in 7- to 8-year-old children: A case-control review. Aust N Z J Obstet Gynaecol. 2015

20. Montoro M.N. Management of hypothyroidism during pregnancy. Clin Obstet Gynecol. 1997, 40:65-80

21. Mestman J.H. Hyperthyroidism in pregnancy. Clin Obstet Gynecol, 1997, 40(1):45-64

22. Roth D.E. Vitamin D supplementation during pregnancy: safety considerations in the design and interpretation of clinical trials. J Perinatol. 2011, Jul; 31(7):449-59.

23. Demirel N., Aydin M., Zenciroglu A., Okumus N., Cetinkaya S., Yildiz Y.T., Ipek M.S. Hyperparathyroidism secondary to maternal hypoparathyroidism and vitamin $D$ deficiency: an uncommon cause of neonatal respiratory distress. Ann Trop Paediatr. 2009 Jun; 29(2):149-54.

24. Callies F., Arlt W., Scholz H.J., Reincke M., Allolio B. Management of hypoparathyroidism during pregnancy - report of twelve cases. Eur J Endocrinol. 1998 Sep; 139(3):284-9.
25. Hovdenak N., Haram K. Influence of mineral and vitamin supplements on pregnancy outcome. Eur J Obstet Gynecol Reprod Biol. 2012 Oct; 164(2):127-32.

26. Csáky-Szunyogh M., Vereczkey A., Kósa Z., Urbán R., Czeizel A.E. Association of maternal diseases during pregnancy with the risk of single ventricular septal defects in the offspring--a population-based case-control study. J Matern Fetal Neonatal Med. 2013 May; 26(8):738-47. doi: 10.3109/14767058.2012.755170. Epub 2013 Jan 15.

27. Chmurzynska A. Fetal programming: link between early nutrition, DNA methylation, and complex diseases. Nutr Rev. 2010; 68:87-98.

28. Brown S.B., Reeves K.W., Bertone-Johnson E.R. Maternal folate exposure in pregnancy and childhood asthma and allergy: a systematic review. Nutrition Reviews, 72: 55-64, 2014

29. Johnson W.G. DNA polymorphism-diet-cofactor-development hypothesis and the gene-teratogen model for schizophrenia and other developmental disorders. Am. J. Med. Genet., 88: 311-323, 1999

30. Lee L.M., Leung C.Y., Tang W.W., Choi H.L., Leung Y.C., McCaffery P.J., Wang C.C., Woolf A.S., Shum A.S. A paradoxical teratogenic mechanism for retinoic acid. Proc Natl Acad Sci USA. 2012 Aug 21; 109(34):13668-73.

31. Rao S., Yajnik C.S., Kanade A., et al. Intake of micronutrient-rich foods in rural Indian mothers is associated with the size of their babies at birth: Pune Maternal Nutrition Study. J Nutr 2001; 131(4):1217-1224.

32. Lun Hon K., Leung A.K.C. Neonatal Lupus Erythematosus. Autoimmune Diseases. 2012; 2012:301274. doi:10.1155/2012/301274.

33. Ritu Khurana, Robert E. Wolf, Systemic Lupus Erythematosus and Pregnancy, Updated: Apr 29, 2014, http://emedicine.medscape.com/ article/335055-overview

34. Polizzi A., Huson S.M., Vincent A. Teratogen update: maternal myasthenia gravis as a cause of congenital arthrogryposis. Teratology. 2000 Nov; 62(5):332-41. Review.

35. Chaudhry S.A., Vignarajah B., Koren G. Myasthenia gravis during pregnancy. Canadian Family Physician. 2012; 58(12):1346-1349.

36. Levy H.L., Ghavami M. Maternal phenylketonuria: a metabolic teratogen. Teratology. 1996 Mar; 53(3):176-84.

37. Prick B.W., Hop W.C., Duvekot J.J. Maternal phenylketonuria and hyperphenylalaninemia in pregnancy: pregnancy complications and neonatal sequelae in untreated and treated pregnancies. Am J Clin Nutr. 2012 Feb; 95(2):374-82.

38. Maillot F., Lilburn M., Baudin J., Morley D.W., Lee P.J. Factors influencing outcomes in the offspring of mothers with phenylketonuria during pregnancy: the importance of variation in maternal blood phenylalanine. Am J Clin Nutr. 2008 Sep; 88(3):700-5.

39. Paula Kiberstis, Leslie Roberts. 2002. It's not just the genes. Science 296:685.

40. Wallingford J.B., Niswander L.A., Shaw G.M., et al. 2013. The continuing challenge of understanding, preventing, and treating neural tube defects. Science 339:1047-1054.

41. Pei L., Zhu H., Ye R., Wu J., Liu J., Ren A., Li Z., Zheng X. (2015), Interaction between the SLC19A1 gene and maternal first trimester fever on offspring neural tube defects. Birth Defects Research Part A: Clinical and Molecular Teratology, 103: 3-11. doi:10.1002/bdra.23257 